\title{
Ecotourism Resources Protection for Sustainability and Law Enforcement Problems in China

\author{
Chang-Qing PANG ${ }^{1}$, * and Guo-Qin $\mathrm{CHEN}^{2}$, Di PANG
}

${ }^{1}$ Jinan Campus, Shandong University of Science and Technology, Jinan, Shandong, China

2 Foreign Languages Department, Zaozhuang University Zaozhuang, Shandong, China

${ }^{3}$ University of Tsukuba, Dept. of Social Sciences, Tsukuba, Japan

*13853184438@163.com, bluesealme2@yahoo.com

${ }^{*}$ Chang-Qing PANG

\section{Key words: Ecotourism, Resources, Protection, Law Enforcement}

\begin{abstract}
Ecotourism resources in China call for protection by strictly making and implementing corresponding laws in spite of the false booming tourism market which has been doing destructive damages to the vulnerable and valuable tourism resources and environment because of the awareness absence of great values and significance of ecotourism, and the absence of laws and enforcement. Based on the detailed analysis of the status quo, we suggest a comprehensive law frame to include clarifying the ownership of tourism resources, setting severe punishment onto those illegal activities and law breakers, banning commercial and industrial development surrounding tourism resources, preventing any man-made scenic sports from being developed, granting the citizens the right to free access to public scenic spots, strengthening law enforcement, civilizing tourists with protection awareness, and beautifying every place to ease the tension of ecotourism resources protection.
\end{abstract}

\section{Conceptual Deficiency of Ecotourism in China}

The concept of ecotourism was first propose by Ceballos Laskurain, the special advisor for IUCN (International Union for the Conservation of Nature and Natural Resources) and received active responses. According to the International Ecotourism Society (TIES), ecotourism is now defined as "responsible travel to natural areas that conserves the environment, sustains the well-being of the local people, and involves interpretation and education" (TIES, 2015). ${ }^{1}$ Additionally, TIES clearly stipulates the corresponding principles as follows:

Minimize physical, social, behavioral, and psychological impacts.

Build environmental and cultural awareness and respect.

Provide positive experiences for both visitors and hosts.

Provide direct financial benefits for conservation. .......2

Unfortunately, while the concept of ecotourism has been well-recognized and implemented in western countries, china is lagging far behind in both understanding the great values and significance of ecotourism and realizing the ultimate purposes of ecotourism, for which the governments should be greatly responsible.

According to investigations, 22 percent of ecological reserves in china have been damaged in different degrees in spite of that the income out of them has reached 5.2 billion RMB, which demonstrates that ecotourism resources are facing great threats confronting the booming tourism, which is due to the inactivity of government enforcement. Although the eight principles by TIES are not substantial laws abide by, they are playing reasonable roles in preserving the nature and safeguarding people's interest. So, those principles should be given great priorities in making laws by states over the world. But driven by strong impetus to collect taxes and fees, almost all the local governments in China encourage excessive development of natural tourism resources, as well as

${ }^{1}$ What is Ecotourism? http://www.ecotourism.org/what-is-ecotourism.06/02/2015.

2 Id. 
building a great number of man-made tourism spots, greatly damaging the surrounding natural resources, which is clearly against the guiding principles of "Minimize physical, social, behavioral, and psychological impacts", and "Build environmental and cultural awareness and respect", 3 just because the local governments lack of the awareness of environment and culture protection.

We believe that ecosystem is of the basic fragile quality due to that it is easily endangered by natural and unnatural destructions to lose its firmness and stability, and that it is easily subjected to excessive market development, finally leading to natural, human and social disasters. Human factors are more destructive than natural ones, which is why we have to call on the governments at all levels to shoulder the responsibly to raise the awareness of natural resources protection.

\section{Destructive Human Factors against Ecotourism}

Ecotourism resources are influenced or destructed by "inner factors" and "outer factors". Inner factors refer to those directly related with tourism activities, while the latter covers the irrational economic development activities close to tourism resources. The following activities or inactivity by the local governments contribute a lot to the tourism resources degradation and damages.

Over-construction and development of tourism resources under the irrational and profit-pursuit ideas by the local governments lead to irrevocable damages to natural and cultural resources by unnecessary adding, mending, fixing etc., either damaging the natural existence or exploiting the beauty of the resources, which is called "destructive constructions". It is not unusual for us to see such incidents happen again and again. The Great Wall, the world-famous scenic spot, has long been recognized and protected as a World Culture Heritage since the year of 1987 by the UNESCO, however, dozens of projects in the name of the Great Wall have been developed allowing commercial activities to boom just on or along the Great Wall which has been degrading the Wall into a long commercial market, for which the Great Wall has lost its unique styles and features.

The local governments are also to be blamed for congesting scenic spots since they are constantly encouraging more and more tourists to visit for the purpose of more profit in spite of considering the capacity of scenic spots, so that the large crowd are constantly pushing great burdens onto the resources thus greatly damaging their existence. For example, the bank pier of a stone bridge in Zhuozheng Garden located in Suzhou City collapsed due to the overburden by too many crowds of people walking over it. Actually, almost all scenic sports in China, whether natural or cultural, are all over crowed, especially in public holidays, thus upsetting the tourists and damaging the resources, which is also due to the inactivity by the local governments for the ignorance of protection mind.

Large-scale commercial development close to tourism resources never stops, such as hotels, restaurants, shopping centers, residences, even factories, in order to attract more and more tourists for greater benefits to the revenue of the local governments. In Hangzhou City, known as the Heaven on the Earth, famous for tea production and tourism, nearly half of its scenic spots are greatly polluted by decomposed tea leftovers from great number of teahouses serving tourists, causing rivers degraded and smelly, damaging the drinking water, soil and air, driving more tourists away from those areas. The second example goes to the Yungang Grottoes, world-famous for its stone Buddha sculptures with several thousand years of history, located in Datong, Shanxi province with thousands of coal mines around the grottoes. With the coal industry booming, the merciless strong wind blows great amount of coal ashes and sand onto the stone sculptures causing great erosion.

Tourists are also responsible for the deterioration of tourism resources since they deliberately or unintentionally involve themselves in the ecotourism destructive forces. Firstly, it is not unusual for some tourists to damage tourism resources impulsively just for fun or playing practical jokes. Secondly, environment destruction is primarily caused by rubbishes left by tourists while they go sightseeing or eating. And then, invisible destructive forces, such as noise, smoke, light, and electricity caused by tourist reasons also greatly influence tourism experience. 


\section{Weak Law Enforcement on Tourism Resources Protection}

Great number of nations are doing great job in making corresponding laws to protect natural tourism resources. France was the first nation to make culture relics protecting law in the world and has been effectively protecting its cultural relics and natural scenic spots with artistic, historic, scientific and legendary significance under the law of Scenery and Cultural Relics Protection Law. The United States specifically rules over tourism resource development, utilizing, and scenic spots protection under specific individual laws. Egypt does a good job with the Law on Authoring Ministry of Tourism to Supervise Developing Tourism Areas. In addition, individual laws are enforced by Japanese government to protect parks, forests, natural reserves, old buildings, culture relics, and urban greenings, and to prevent pollution. Those laws have been contributing greatly to the protection of culture relics, nature resources and ecotourism. However, China is still having a long way to go. Up to now, the relative laws and regulations are found as follows:

Firstly, article nine of Constitution of the People's Republic of China says: "The state ensures the rational use of natural resources and protects rare animals and plants. Appropriation or damaging of natural resources by any organization or individual by whatever means is prohibited." 4 Although the Constitution enjoys the highest legal power, only principles on resource protection are not helpful in dealing with actual situations. Specific rules have to be made in specific laws to tackle practical problems. Secondly, the newly adopted Environment Protection Law of the People's Republic of China focuses on the governments' supervising responsibilities on environmental protection, and again, no specific measures concerning natural resource development are stipulated in the law, which is a great loss for such an important law.5Thirdly, such regulations as the Natural Reserves Regulations and Provisional Regulations on Scenic Areas by the State Council only impose the minimum punishment on those lawbreakers who damage natural reserves or scenic areas, which is equal to encouraging law violations since the lawbreakers may have more gains than losses, or they can easily escape from the punishment. And most importantly, although Tourism Law of the People's Republic of China was newly put into force in 2013, which should have included as many as possible matters relating to tourism development, management, administration, protection etc., narrow coverage makes the law very defective since it just regulates travel contracts between travel agencies and tourists too much, instead of caring about natural resource protection and ecotourism, which is no doubt a huge indiscretion.

The major defects of the above laws and regulations can be summarized as follows:

Firstly, we have been encountering the inefficiency in quality and deficiency in numbers of such laws due to the common belief that the nature is born to serve the people, hence it is too late for our lawmakers and common people to realize that we have to live on our nature, not vice versa, which is why we are left far behind western countries in regulating ecotourism. Secondly, we are desperately in need of a unified and comprehensive law to regulate everything about tourism, where ecotourism protection has to be the major part. The isolated law articles are scattered over numbers of laws and regulations, some of which contradict each other damaging the authority of the laws, let alone providing effective protections on ecosystem. Thirdly, local governments and agencies are given different powers to regulate ecosystem protection, and they make different decisions, thus confusing the law enforcement efforts, which ultimately leads to the weakness of law enforcement on tourism resources. More seriously, some local governments are pursuing their own interest by all means ignoring the interest of all citizens. In addition, lack of operability of such laws and stipulations influences the law enforcement effect, since obscure articles do not provide effective guidance for law enforcement officers to take actions, thus diminishing the authority and effectiveness of such laws and regulations. Furthermore, some law enforcement officers are undertrained, unqualified or even corrupted in enforcing such laws, which is not an uncommon phenomenon in China, thus encouraging law breakers to take further actions to brutally damage or destroy ecotourism resources.

\footnotetext{
${ }^{4}$ Article Nine of Constitution of the People's Republic of China

5 See Environment Protection Law of the People`s Republic of China.
} 


\section{What is Law Going to Do about Ecotourism?}

The tourism resources are seriously endangered in that no effective laws are to regulate resource development, maintenance, and protection in spite of that we have implemented Natural Reserves Regulations and Provisional Regulations on Scenic Areas, Tourism Law of the People's Republic of China, Environment Protection Law of the People's Republic of China, etc., since the mentioned above either fail to provide specific protective measures, or just focus on trifle matters ,so it is urgent to make such a law as Tourism Resources Protection Law immediately before the terrible situation gets worse, where the following items have to be included.

(1) Since tourism resources are ineffectively protected by rules scattered over different laws and regulations with less operability and compatibility with each other, a basic and comprehensive tourism law has to be made and implemented to adapt to the fast booming tourism situation in China. Experiences can be learned from The U.S. In 1916, the United States established the national park administration agency and passed the Yellow Stone Act and the National Park Act. An absence of such a law will leave tourism resources under less protection and more serious deterioration.

(2) The new law has to clearly decide on the ownership of different tourism resources, which is ambiguous for the time being. Accordingly, tourism resources are state-owned, but factually, local governments, government agencies, event enterprises are all able to occupy, develop, and exploit the resources, where no effective supervision could be taken. The new law is taking the great responsivity to clarify the ownership and set severe punishment onto those illegal activities and law breakers.

(3) Law enforcement has to be strengthened. Weak penalties, regional protectionism, ambiguous governance all contribute to the week law enforcement. In addition, the public are given no right to supervise the law enforcement activities, which encourages the law breakers with restraint. More than that, the practical approach to punishing law breakers is only to impose a fine, which just takes a small portion of their profits, hence adding to the ignorance of the power and dignity of laws. So, we suggest that both severe civil punishment (high level of fine) and criminal punishment should be introduced and implemented to raise the public awareness of the high cost of law offenses.

(4) Commercial and industrial development surrounding tourism resources have to be strictly banned. Protection zones have to be established to make sure the commercial development do not influence those resources, for they can only be used for spiritual relaxing rather than commercial activities. In ancient China, wood cutting or similar activities within the protection zone (usually several miles to dozens of miles) were forbidden around the Five Sacred Mountains (Taishan, Hengshan, Huashan, Hengshan and Songshan) throughout the state. In America, hunting and tree-cutting have been prohibited since the Yellow Stone National Park was found and established, and the native Indians also moved out of the park region for resource protection. In Germany, the Alps National Park covers a large area of around 300 square kilometers, where no cableways are established, and only outside of park can we find some cableways to transport the passengers. Hence, we call for complete banning on these activities.

(5) Any man-made scenic sports have to be forbidden. Ecotourism values natural ecosystem and repels human intervention. Natural sceneries and culture relics always speak for themselves, and any human intervention threatens their life and undermines the tourist experiences. Man-made ones, such as thousands of Buddha statues and temples, are repeatedly established throughout the state only to attract tourists to pay for their luck, which costs too much and encourages superstition. Some man-made scenic spots are developed based on some fabricated folktales, mythology, and historic figures, actually without any documentary ground, some even spreading superstitious beliefs, which is heavily against our human civilization. So, such fabrications have to be completely prohibited by law.

(6) Tourists should be granted the free access to scenic spots by the law. Natural resources and cultural relics belong to all human beings. Any charges on tourists for the access do not explain themselves in any ways, let alone over-charges. The maintenance and protection cost should be shouldered by the local government since all the tourists are also taxpayers, except for minimum management expenses. However, tourists are charged higher tickets fees and become the cash 
machine for local governments, which again stimulates more expanding development. The law has to set the basic principle that all natural resources and cultural relics are only for the purpose of serving the citizens for free on a non-profit basis, demonstrating that local governments are prohibited from making money from running such resource parks, and what they have to do is to serve the citizens.

(7) The destruction of tourism resources is also due to tourists, who are actually exploring natural resources for their own interest just because they pay for them, without the slightest idea of that they just pay for enjoyment instead of destroying. They are ignorant of their illegal behaviors by leaving rubbish everywhere and deliberately damaging tourism resources. We suggest severe civil and criminal punishments on their illegal offenses in the new law, to help tourists understand the importance of tourism resource protection and the fatal consequences of illegal offenses.

\section{Additional Countermeasures}

Law does not solve all the problems, and countermeasures also play key roles in ecotourism protection. We are facing a difficult situation that millions of tourists flock to a few famous scenic spots at the same time in spite of traveling thousands of miles, which is mainly due to the scarce tourism resources around us. If our hometowns, cities, and neighborhoods are beautifully built like gardens and we have our own fancy sceneries at hand, we would not like to travel that far to add trouble to those crowded scenic spots, since we can enjoy the great nature at home, even looking through the windows. So what we urgently need now is to improve and beautify our living environment by getting rid of pollutions, improving infrastructures, expanding more greenery. Once everyone is satisfied with the beautiful sceneries at home, he feels no rush to visit elsewhere, which is great relief to the burden of limited famous tourism resources.

\section{Conclusion}

The article begins with reveling conceptual deficiency in understanding Chinese tourism, then analyzes destructive human factors against ecotourism in China, and primarily puts forward suggestions to strength lawmaking and enforcement to regulate the ownership and management of different kinds of tourism resources to clarify and ensure the citizens ' rights to tourism resources, highlighting ecotourism values and repelling human interventions.

\section{References:}

[1] Guotang Yang, Tourism laws and Regulations, Shanghai Jiao Tong University Press, Shanghai, (2009).

[2] Fubin Yang, A Collection of Western Tourism Laws, Social Science Documents Press, Beijing, (2005).

[3] Shuo Ding, Law enforcement on Eco-tourism, J. Legality and Society, Kunming, April (2012).

[4]Yueyue Zhao, Eco-tourism law Study, J. Journal of Jilin University, Changchun, August (2010).

[5] Bohuai Li, A Collection of Tourism Laws and Cases, Sichuan University Press, Chengdu, (2013).

[6] Information on http://www.ecotourism.org/what-is-ecotourism 